\title{
Isolated Spinal Rosai-Dorfman Disease: Challenge of Management
}

\author{
Amer Alshurbaji ${ }^{1}$, Alhareth Ma'aya ${ }^{1 *}$, Wagdy Al-Kadasi ${ }^{1}$ and Duaa Alshurbaji ${ }^{1,2}$ \\ ${ }^{1}$ Department of Neurosurgery, King Hussein Medical Center, Jordan \\ ${ }^{2}$ Department of Histopathology, King Hussein Medical Center, Jordan
}

Submission: February 25, 2017; Published: April 07, 2017

*Corresponding author: Alhareth Ma’aya, Department of Neurosurgery, King Hussein Medical Center, Amman, Jordan, Email: alhareth1947@gmail.com

\begin{abstract}
Rosai-Dorfman disease (RDD); an uncommon disease of idiopathic histoproliferative disorder that typically presents with systemic symptoms and painless cervical lymphadenopathy. Spinal involvement is comparatively rare and isolated spinal RDD is extremely rare entity. We present our case of isolated spinal RDD in a 35-year-old man presented with extradural spinal lesion.
\end{abstract}

Keywords: Rosai-dorfman disease; Sinus histocytiosis; Lymphadenopathy

Abbreviations: RDD: Rosai Dorfman Disease; EBRT: External Beam Radiotherapy; MRI: Magnetic Resonance Imaging; CNS: Central Nervous System; ESR: Erythrocyte Sedimentation Rate

\section{Introduction}

Rosai-Dorfman disease (benign lymphohistiocytosis) typically involves lymph nodes, clinically present as painless cervical lymphadenopathy, and fever (massive lymphadenopathy with sinus histocytiosis). Blood tests show leukocytosis, elevated ESR and polyclonal hypergammaglobulinemia. First reported by Destombes in 1965. In 1969, two pathologists, Juan Rosai and Ronald Dorfman, reported a distinct histiocytic disorder in several patients with massive enlargement of the lymph nodes, as well as other symptoms. They named this condition sinus histiocytosis with massive lymphadenopathy, and thus have since come to be known as Rosai-Dorfman disease.

\section{The case}

A 35 years old man presented to outpatient clinic with 2 months' history of progressive low back pain and asymmetrical lower limb weakness with no sphincters disturbances, with no history of prior illnesses. Neurological examination revealed power $4 / 5$ in right foot dorsi and planter flexion and 4+/5 in left foot dorsi and planter flexion. MRI of lumbosacral area showed homogenous enhancing extradural lesion extending from L3 level till the sacrum with bony invasion. The extradural lesion was hypointense on T1WI, hypointense on T2WI with homogeneous enhancement in post contrast images (Figure 1 \& 2). Routine hematological and biochemical studies were normal. The patient underwent microscopic excision of the extradural lesion with subtotal excision of the lesion, which was insignificantly vascular, firm and grayish-yellow in color. Postoperative course was uneventful. Histopathology revealed a mixed lymphoplasmacytic inflammatory infiltrate containing sheets of large and foamy histiocytes; some of these histiocytes engulfed a large number of lymphocytes and plasma cells, corresponding to emperipolesis. By immunohistochemistry, histiocytic cells were positive for S100 protein (Figure 3), as well as for CD68 (Figure 4).

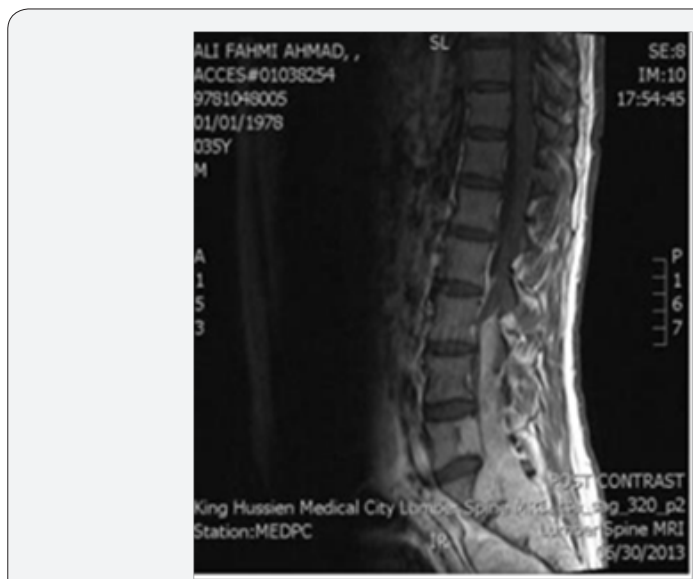

Figure 1: T1 contrasted sagittal MRI showed homogenous enhancement of extradural lesion with bony invasion. 


\section{Open Access Journal of Neurology \& Neurosurgery}

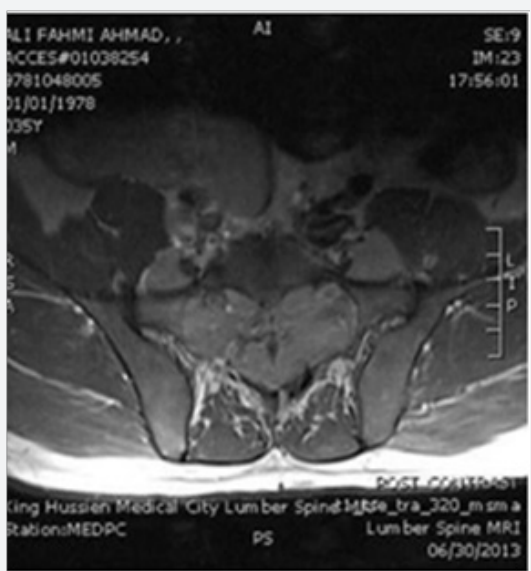

Figure 2: T1 contrasted axial MRI showed homogenous enhancement of extradural lesion with bony invasion.

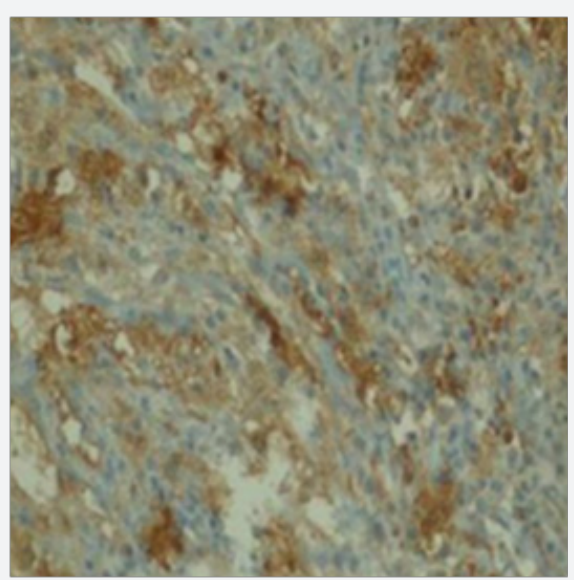

Figure 3: The large histiocytic cells are positive for S100.

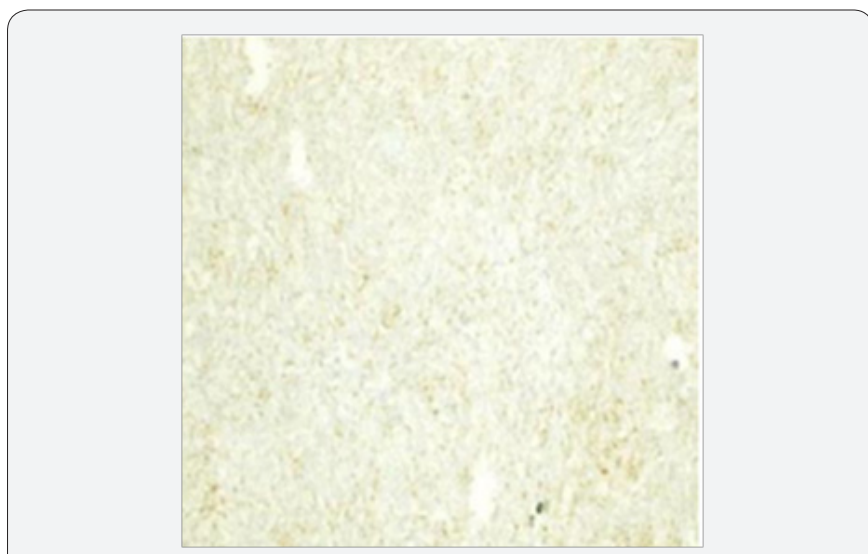

Figure 4: The large histiocytic cells are positive for CD 68

Post operatively back pain and weakness improved significantly, no lymphadenopathy or systemic masses were identified on admission and on follow up. The case was discussed with oncology team and the patient was treated with a course of EBRT to L4-S4 area (20 Gray/5 Fractions) which was tolerated with no major side effect. Follow up MRI revealed reduction in the size of the lesion (Figure 5).

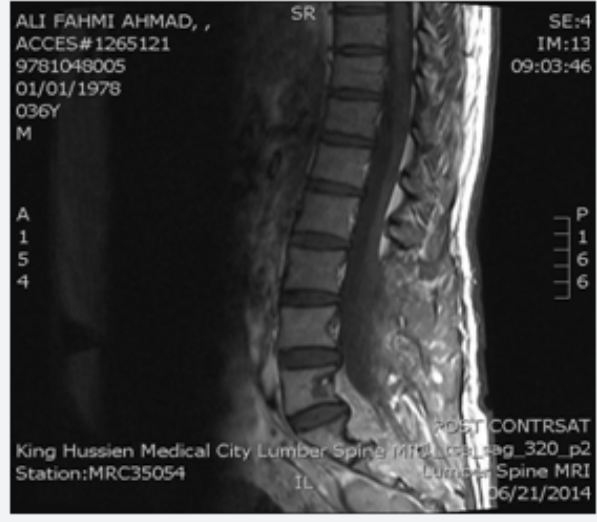

Figure 5: Post-operative and radiotherapy T1 contrasted sagittal MRI showed significant reduction in size and control of the disease.

\section{Discussion}

RDD mainly presents in children and young adult (mean age of 20.6 years and range 1-74 years old), here is a slight male predominance (male: female $=1.4: 1$ ) [1]. CNS involvement is reported in less than $5 \%$ and extranodal involvement in more than $90 \%$ of patients presenting with cervical lymphadenopathy, and in $43 \%$ of cases including paranasal sinuses, skin, bone and Orbit [2].

MR imaging characteristics of RDD can be variable showing either low or isointense on T1- and T2-weighted images with an intense and uniform contrast enhancement [3]. Microscopically RDD is characterized by infiltration of histiocytes, B and T lymphocytes and plasma cells. Emperipolesis is typical of RDD of the leptomeninges but is absent in $30 \%$ of cases [3]. By immunocytochemical Studies, expression of CD68, CD31, a1 antitrypsin and a1 antichymotrypsin are positive both for mononuclear cells and dendritic cells, but a positive expression of S100 is found only for dendritic cells.

CD1a is not expressed by any cells in RDD as explained by Purav et al. [4] in a recent series including 10 cases of RDD in the central nervous system. RDD diagnosis is based entirely on histopathology and immuno histochemistry [4]. Most of spinal RDD are managed surgically with variable degrees of tumor excision and many of the cases benefit from postoperative steroids, adjuvant radiotherapy and chemotherapy with vinca alkaloids and alkylating agents [5]. Horneff et al. reported a good response of RDD to methotrexate and mercaptopurine. Aouba et al. noted a patient with systemic RDD was asymptomatic after 3 cycles of cladribine treatment.

The etiology of RDD is presumed to be reactive in nature, as no evidence of clonality has been demonstrated by molecular analysis. There is possible association with infective agents like human herpes virus 6 and parvovirus B19 have been suggested in few studies [6]. Roy et al [7] reviewing the literature reveled at least 35 previously reported cases with spinal involvement, although isolated spinal involvement was seen only in six cases 
of them [7]. Therefore, our case is the eighth case with isolated spinal involvement reported in the literature.

\section{Conclusion}

The diagnosis of Spinal RDD is challenging and preoperatively the condition is often mistaken for meningioma or other extradural lesions. Because this disease is so rare, no large studies have been performed, and there is no established, widely accepted treatment. Surgical removal of spinal lesions is an effective treatment. Post-operative radiotherapy appears effective; however, more research is needed to clarify their use and the effectiveness of other treatment options such as chemotherapy, as well as long term outcomes after treatment [8].

\section{References}

1. Huang TY, Shu-Ha NG, Sheung-Fat K, Wong HF, Yao-Liang C, et al. (2009) Extranodal Rosai-Dorfman disease with paranasal sinuses and intracranial involvement: a case report. Chinese J of Radiology 34(3): 191-196.
2. R Kumar, Singhal U, Mahapatra AK (2011) Intracranial Rosai- Dorfman syndrome. Pan Arab Journal of Neurosurgery 15(1): 58-63.

3. Al-Saad K (2005) ExtranodalRosai-Dorfman disease with multifocal bone and epidural involvement causing recurrent spinal cord compression. Pediatr Dev Pathol 8(5): 593-598.

4. Purav P, Ganapathy K, Mallikarjuna VS, Annapurneswari S, Kalyanaraman S, et al. (2005) Rosai-Dorfman disease of the central nervous system. J Clin Neurosci 12(6): 656-659.

5. Tubbs RS (2005) Spinal cord compression as a result of Rosai-Dorfman disease of the upper cervical spine in a child. Childs Nerv Syst 21(11): 951-954.

6. Mehraein Y, Wanger M, Remberger K, Fuzesi L, Middel P, et al. (2006) Parvovirus B 19 Detected in Rosai-Dorfman disease in nodal and extranodalmainfestations. J clinPathol 59(12): 1320-1326.

7. Roy C, Saha A, Roy S, Ghosh A (2012) Extranodal Rosai-Dorfman Disease presenting as spinal extradural lesion: A case report with review of literature. J Can Res Ther 8(4): 647-649.

8. Said R, Abi-Fadel F, Talwar J, Attallah JP, Dilawari A (2011) Intracranial Rosai-Dorfman: a clinical challenge. Neurologist 17(2): 117-119.

\section{Your next submission with Juniper Publishers will reach you the below assets}

- Quality Editorial service

- Swift Peer Review

- Reprints availability

- E-prints Service

- Manuscript Podcast for convenient understanding

- Global attainment for your research

- Manuscript accessibility in different formats

( Pdf, E-pub, Full Text, Audio)

- Unceasing customer service

Track the below URL for one-step submission https://juniperpublishers.com/online-submission.php 